\begin{tabular}{l}
\hline OPEN O ACCESS Freely available online \\
http://www.banglajol.info/index.php/BJID/index \\
Original Article \\
Bangladesh Journal of Infectious Diseases \\
June 2015, Volume 2, Number 1 \\
ISSN (online) 2411-670X \\
ISSN (Print) 2411-4820 \\
\hline
\end{tabular}

\title{
Antibiotic Sensitivity of Bacteria Causing Urinary Tract Infection
}

\author{
Rezina Parveen ${ }^{1}$, Md. Abdullah Yusuf ${ }^{2}$, Ishrat Sharmin $^{3}$, Md. Saiful Islam ${ }^{4}$, Ina Rahim ${ }^{5}$
}

${ }^{1}$ Associate Professor, Department of Pathology \& Microbiology, Dhaka Dental College, Dhaka, Bangladesh; ${ }^{2}$ Assistant Professor, National Institute of Neurosciences \& Hospital, Dhaka, Bangladesh; ${ }^{3}$ Assistant Professor, Department of Pathology and Microbiology, Dhaka Dental College, Dhaka, Bangladesh; ${ }^{4}$ Lecturer, Department of Microbiology, Shaheed Suhrawardy Medical College, Dhaka, Bangladesh; ${ }^{5}$ Junior consultant (Clinical Pathology), Dhaka Dental College \& Hospital, Dhaka, Bangladesh

[Received: 1 January 2015; Accepted: 15 March 2015; Published: 1 June 2015]

\begin{abstract}
Background: Urinary tract infection is very common in both male and female. Objectives: The purpose of the present study was to see the antibiotic sensitivity pattern of isolated from urinary tract infected patients. Methodology: This cross sectional study was carried out in Dhaka Medical College Hospital, Dhaka for a period of 12 months. Clinically diagnosed cases of urinary tract infection irrespective of age and sex having pus cells $\geq 5 / \mathrm{HPF}$ in the deposits of centrifuged urine were selected as study population. Data regarding organisms causing UTI and their antibiotic sensitivity patterns were collected. For urine culture the urine samples were inoculated on HiCrome UTI agar, CLED agar, 5\% sheep blood agar and MacConkey's agar media with a calibrated loop having diameter of $1.45 \mathrm{~mm}$ which contains $0.001 \mathrm{ml}$ of urine. The inoculation at $37^{\circ} \mathrm{C}$ for 24 hours and CFU count of $10^{5} / \mathrm{ml}$ of urine were considered positive for UTI. Identification of bacteria was done by standard biochemical techniques and their distinct colony characteristics. All the isolated organisms were tested for antimicrobial sensitivity against different antimicrobial agents by disc diffusion method on Mueller-Hinton agar plates. Result: Diagnosis of bacteria causing UTI with their sensitivity to different antibiotics was performed with a total of 300 samples from both male (38.66\%) and female (61.33\%) of different age groups. Among 300 samples 107 strains were isolated. Out of 107 identified strains, 95(31.67\%) samples showed single growth and 6(2\%) samples showed mixed growth. Escherichia coli $(64.49 \%)$ was found to be the predominant organism. Regarding antimicrobial sensitivity pattern Esch. coli showed 98.55 to $63.77 \%$ sensitivity to imipenem, amikacin, ceftazidime and nitrofurantoin. Other isolated organisms showed 50 to $100 \%$ sensitivity to ceftazidime, amikacin, imipenem except Klebsiella, Pseudomonas and enterococci spp. which showed $40 \%$ and less sensitivity. Conclusion: In conclusion Escherichia coli is the most commonly isolated bacteria which is highly sensitive to imipenem. [Bangladesh J Infect Dis 2015;2(1):13-18]

Keywords: Antimicrobial sensitivity; urinary tract infection; bacterial pathogens

[How to Cite this article Parveen R, Yusuf MA, Sharmin I, Islam MS, Rahim I. Antibiotic Sensitivity of bacteria Causing Urinary Tract Infection. Bangladesh J Infect Dis 2015;2(1):13-18]

Corresponding author: Dr. Rezina Parveen, Associate Professor, Department of Pathology and Microbiology, Dhaka Dental College, Mirpur-14, Dhaka, Bangladesh; Email: parveenrezina@gmail.com ; Cell no.: +8801715425856

Conflict of Interest: Authors have declared no conflict of interest.

Contributions to authors: RP has contributed from protocol preparation to manuscript writing as well as in data collection.

MAY, IS, MSI \& IR have prepared and have revised the manuscript.
\end{abstract}




\section{Introduction}

Urinary tract infection (UTI) is associated with multiplication of organisms in the urinary tract and is defined by the presence of more than $10^{5}$ organisms per $\mathrm{ml}$ in a midstream sample of urine ${ }^{1}$. It is estimated that about $35.0 \%$ of healthy women suffer symptoms of UTI at some time in their life ${ }^{2}$. Urinary tract infection is caused mainly by normal bowel flora-principally Escherichia coli, responsible for $\geq 75 \%$ of cases $^{3}$. Other Gram negative Enterobacteriaeceae, Gram positive Enterococcus faecalis and Staphylococcus saprophyticus are responsible for remainder of most commonly acquired $\mathrm{UTI}^{4}$. Nosocomial infections are frequently caused by Enterococcus faecalis, Klebsiella species, Enterobacter species, Citobacter species and Pseudomonas aeruginosa. Urinary tract infection is the leading cause of Gramnegative sepsis in hospitalized patients ${ }^{6}$. Urinary tract infections are more common in women than in men though male over 60 years with prostatic hypertrophy are the exceptions ${ }^{7}$. Women are more prone to UTIs than men because in females, the urethra is much shorter \& closer to the anus than in males ${ }^{8}$. Urine samples are among the most common specimen sent for microbiology studies. A large laboratory may examine 200-300 urine samples each day'. This heavy workload reflects the frequency of UTI both in general practice and in hospital settings and demands a cost effective method for the diagnosis of UTIs.

One of the most important and readily available laboratory tests in patients with suspected UTI is detection of pyuria. Pyuria is present in almost all symptomatic UTIs and its absence should strongly suggest another diagnosis. Thus, the quantification of pyuria is usually made on the basis of direct microscopic examination of urinary sediment from a centrifuged specimen ${ }^{10}$. White blood cells $>5 / \mathrm{HPF}$ is considered to be significant ${ }^{11}$. The aim of the microbiology laboratory in the management of UTI is accurate and timely diagnosis with appropriate antimicrobial sensitivity testing thus reducing morbidity $^{7}$. The increase in resistance of microorganisms to antimicrobial agents, especially in hospitalized patients needs identification of pathogens ${ }^{11}$. Therapeutic decision should be based on accurate, up-to-date antimicrobial susceptibility pattern. Rapid and accurate diagnosis, along with early initiation of appropriate antibiotic therapy has great potential to minimize the risk of a poor outcome. It also reduces chronicity \& drug resistance, decreasing patient's sufferings and financial expenditure ${ }^{8}$. For this reason, knowledge of the etiological agents of UTIs and their antimicrobial resistance patterns in specific geographical locations may aid clinicians in choosing the appropriate antimicrobial empirical treatment. Thereby the study was undertaken to find out the most frequent causative organisms of UTI and to determine the antibiotic susceptibility patterns of microbial agents isolated from urine culture in order to facilitate better treatment and management of UTIs.

\section{Methodology}

This cross sectional study was carried out among out-patient department and in-patient department of Dhaka Medical College Hospital, Dhaka for a period of 12 months. Clinically diagnosed cases of urinary tract infection irrespective of age and sex having pus cells $\geq 5 / \mathrm{HPF}$ in the deposits of centrifuged urine were selected for the purpose of the study during the study period. Patients having pus cells $<5 / \mathrm{HPF}$ in a centrifuged urine sample were excluded from this study. The necessary information was collected using a structured questionnaire to assess the study subject. Data regarding organisms causing UTI and their antibiotic sensitivity patterns were collected. All study subjects were advised to collect the midstream urine sample in wide-mouthed sterile containers. In case of female, they were instructed to clean the area around the urethral opening with clean water and collect the urine with labia held apart. Samples were processed within 1 hour of collection. For direct microscopy, $5 \mathrm{ml}$ of urine was centrifuged at $1500-2500 \mathrm{rpm}$ for 5 minutes. One drop of sediment was taken on a clean glass slide, covered with a cover slip and was examined under light microscope using $10 \mathrm{x}$ and $40 \mathrm{x}$ magnifications. The presence of pus cells $\geq 5 / \mathrm{HPF}$ was considered to be significant pyuria ${ }^{8}$. For urine culture the urine samples were inoculated on HiCrome UTI agar, CLED agar, 5\% sheep blood agar and MacConkey's agar media with a calibrated loop having diameter of $1.45 \mathrm{~mm}$ which contains $0.001 \mathrm{ml}$ of urine. The inoculation at $37^{\circ} \mathrm{C}$ for 24 hours and CFU count of $105 / \mathrm{ml}$ of urine were considered positive for UTI. Identification of organism was done by standard biochemical techniques $^{11}$ and their distinct colony characteristics. All the isolated organisms were tested for antimicrobial sensitivity against different antimicrobial agents by disc diffusion method on Mueller-Hinton agar plates ${ }^{12}$. Antibiotic discs were purchased from commercial source (Oxoid Ltd, UK). Plate was dried in an incubator at $37^{\circ} \mathrm{C}$ for 30 minutes. With a sterile inoculating wire loop five 
colonies of the test organisms were taken and were emulsified in $5 \mathrm{ml}$ of sterile normal saline ${ }^{13}$. The turbidity of the inoculum in the test tube was adjusted by adding more bacteria or more sterile saline to turbidity equivalent to that of 0.5 McFarland's nephelometric standard ${ }^{11}$ which approximately corresponds to $1.5 \times 10^{8}$ organisms/ ml. A sterile cotton swab was immersed in the bacterial suspension and the excess broth was removed by rotating the swab with firm pressure against the side of the tube. The swab was then streaked evenly on the dried surface of plate in 3 different plains by rotating the plate approximately $60^{\circ}$ angle each time to get uniform distribution of the inoculums. A final circular motion was made around the rim with the swab. The inoculum was allowed to dry for 5 minutes at room temperature with the lid closed. The discs were then placed on the inoculated surface by a sterile fine tipped forceps $15 \mathrm{~mm}$ away from the edge of the petri dishes and having $25 \mathrm{~mm}$ gap in between two discs. Six discs were placed $(90 \mathrm{~mm}$ petri dish). The plates were then inverted and were incubated aerobically at $37^{\circ} \mathrm{C}$ for $18-24$ hours. Interpretation of results was done using the zone sizes. Zone of inhibition of growth produced by each drug was considered into the three susceptibility categories, namely sensitive (S), intermediate (I) and resistant (R). All bacteria were assayed against the following antimicrobial agents: amoxicillin $(30 \mu \mathrm{g})$, Cephradine $(30 \mu \mathrm{g})$, cotrimoxazole $(25 \mu \mathrm{g})$, cefotaxime $(30 \mu \mathrm{g})$, ceftazidime $(30 \mu \mathrm{g})$, ceftriaxone $(30 \mu \mathrm{g})$, ciprofloxacin $(5 \mu \mathrm{g})$, nalidixic acid $(30 \mu \mathrm{g})$, nitrofurantoin $(300 \mu \mathrm{g})$, gentamicin $(10 \mu \mathrm{g})$, doxicycline $(30 \mu \mathrm{g})$, imipenem $(10 \mu \mathrm{g})$, aztronam $(30 \mu \mathrm{g})$, amikacin $(30 \mu \mathrm{g})$.

\section{Results}

A total 300 clinically diagnosed UTI cases having pus cells $\geq 5 / \mathrm{HPF}$ were included in this study. Most of them (31.33\%) were in the age group of 21-30 years (Table 1).

Table 1: Distribution of Positive Cases of UTI Causing In Different Age Groups (n=300)

\begin{tabular}{lcc}
\hline $\begin{array}{l}\text { Age group } \\
\text { (years) }\end{array}$ & Frequency & Percentage \\
\hline$\leq 10$ & 20 & 6.66 \\
$11-20$ & 42 & 14.00 \\
$21-30$ & 94 & 31.33 \\
$31-40$ & 72 & 24.00 \\
$41-50$ & 29 & 9.67 \\
$51-60$ & 23 & 7.67 \\
$>60$ & 20 & 6.67 \\
Total & $\mathbf{3 0 0}$ & $\mathbf{1 0 0 . 0 0}$ \\
\hline
\end{tabular}

Bangladesh J Infect Dis
Among 300 samples, 95(31.67\%) samples showed growth of single organism, 6(2\%) samples showed mixed growth and 199(66.33\%) samples yielded no growth (Figure I). Among 116 urine samples collected from males, $35(34.65 \%)$ samples showed growth of organism. 184 urine samples collected from females, 66(65.35\%) samples yielded growth of organism. The difference was not statistically significant $(\mathrm{p}>0.05)($ Table 2).

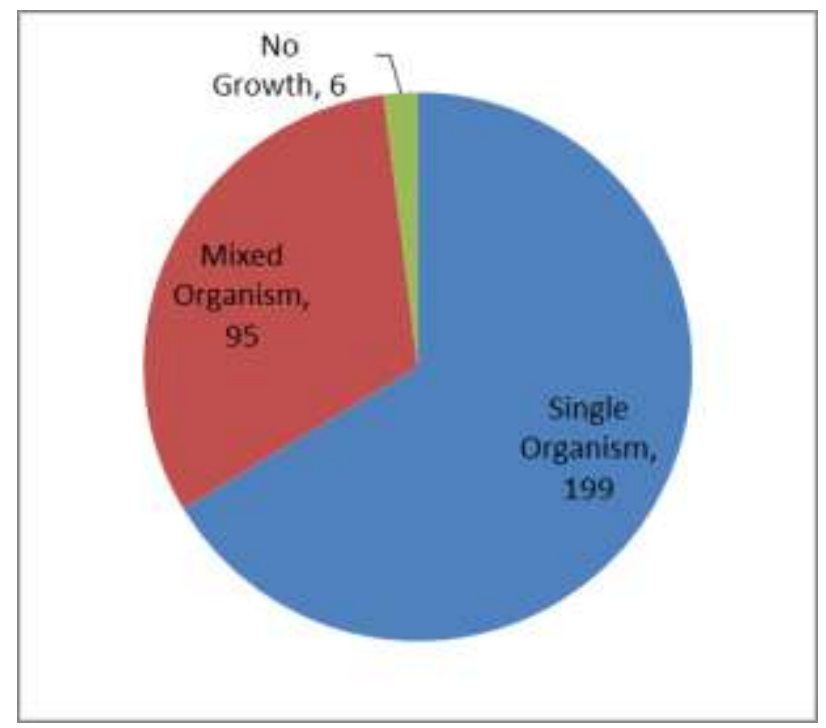

Figure I: Pie diagram shows the results of urine culture

Total 107 strains were isolated from 101 culture positive samples. Among these Esch. coli (64.49\%) was the most common aetiologic agents followed by Klebsiella species (11.21\%), Pseudomonas spp. (9.35\%), Enterococcus faecalis (5.61\%), Proteus species (3.74\%), Staphylococcus saprophyticus $(2.80 \%)$ and Enterobacter species $(2.80 \%)$ in descending order (Table 3).

Table 2: Sex distribution of culture positive and culture negative cases among the study population $(\mathbf{n}=\mathbf{3 0 0})$

\begin{tabular}{llll}
\hline Culture & \multicolumn{1}{c}{ Male } & \multicolumn{1}{c}{ Female } & Total \\
\hline Positive & $35(34.65 \%)$ & $66(65.35 \%)$ & $101(100 \%)$ \\
Negative & $81(40.70 \%)$ & $118(59.30 \%)$ & $199(100 \%)$ \\
Total & $\mathbf{1 1 6}(\mathbf{3 8 . 6 7 \%})$ & $\mathbf{1 8 4}(\mathbf{6 1 . 3 3 \%})$ & $\mathbf{3 0 0}(\mathbf{1 0 0 \%})$ \\
\hline$\chi^{2}=1.68 ; \mathrm{p}>0.05$ & &
\end{tabular}

Regarding the sensitivity towards antibiotics, Esch. coli was found to be most sensitive to imipenem $(98.55 \%)$ followed by amikacin $(82.61 \%)$ and ceftazidime $(82.61 \%)$ followed by cefotaxim $(65.22 \%)$, nitrofurantoin $(63.77 \%)$. Esch.coli was found to be least sensitive to doxicycline (11.59\%), nalidixic acid (17.39\%), amoxicillin(23.19\%), cotrimoxazole $(24.64 \%)$ and cephradine (24.63\%).

June 2015 | Volume 2 Number 1 
High efficacy of imipenem (91.67\%), amikacin (75\%) followed by nitrofurantoin $(66.67 \%)$ was observed against the Klebsiella spp. It was found that Pseudomonas spp. was found to be sensitive only to imipenem which was $90 \%$. Amikacin and imipenem were highly effective (100\%) against Staphylococcus saprophyticus followed by cefotaxim $(75 \%)$, ceftazidime $(75 \%)$, ceftriaxone $(75 \%)$ and ciprofloxacin (75\%). The antimicrobial sensitivity pattern was shown in Table 4.

Table 3: Isolation of Different Organisms among Culture Positive Cases $(n=107)$

\begin{tabular}{lccc}
\hline Isolated Bacteria & Single & Mixed & Total \\
\hline Escherichia coli & 64 & 05 & $69(64.49)$ \\
Klebsiella spp. & 11 & 01 & $12(11.21)$ \\
Pseudomonas spp. & 08 & 02 & $10(9.35)$ \\
Enterococcus spp. & 03 & 03 & $06(5.61)$ \\
Proteus spp. & 04 & 00 & $04(3.74)$ \\
Sta. saprophyticus & 03 & 00 & $03(2.80)$ \\
Enterobacter spp. & 02 & 01 & $03(2.80)$ \\
Total & $\mathbf{9 5}$ & $\mathbf{1 2}$ & $\mathbf{1 0 7}(\mathbf{1 0 0})$ \\
\hline
\end{tabular}

Figures in parentheses represent percentage

\section{Discussion}

A total 300 samples of urine from clinically diagnosed UTI cases having pus cell $\geq 5 / \mathrm{HPF}$ were examined. Of them, 95(31.67\%) samples showed single growth, 6(2\%) showed mixed growth and $199(66.33 \%)$ samples yielded no growth. From
101(33.67\%) culture positive samples, 107 strains were isolated, of which 95 strains were from 95 samples of single growth and $12(6 \times 2)$ strains were from 6 samples of mixed growth.

In the present study, from 101 culture positive cases a total 107 strains were isolated. Of which, 69(64.49\%) were Esch.coli followed by $12(11.21 \%)$ Klebsiella spp, 10(9.35\%) Pseudomonas spp, 6(5.61\%) Enterococci spp, 4(3.74\%) Proteus spp, $3(2.80 \%)$ Staph saprophyticus and 3(2.80\%) Enterobacter spp. Sharmin ${ }^{22}$ from Bangladesh reported Esch. coli as the predominant (53.2\%) organism. Chowdhury et $\mathrm{al}^{15}$ reported $64 \%$, Khaleque et $\mathrm{al}^{16}$ showed $63.4 \%$, Talukder ${ }^{29}$ showed $64 \%$ and Hossain et $\mathrm{al}^{17}$ showed $60 \%$ detected organism as Esch. coli. These findings are comparable with the findings of the present study. However, this study differs from study done by Bhuiyan and $\mathrm{Abdullah}^{18}$, Islam et $\mathrm{al}^{4}$ from Bangladesh and Hames and Rice ${ }^{19}$ from University of Oklahoma. They reported $92 \%, 73.8 \%$ and $90 \%$ Esch. coli from urine respectively. In the present study, the second most common organism was Klebsiella spp. $(9.35 \%)$. Kawser ${ }^{20}$ from Bangladesh worked on ICU patients of different hospital and found that the second most common organism was Klebsiella species $(10.7 \%)$. This finding is in accordance with the finding of the present study but differ from Shahnaz et $\mathrm{al}^{21}$ who reported next common organism was Pseudomonas spp. (18\%).

Table 4: Antibiotic Susceptibility Observed Among the Bacterial Species Causing UTI

\begin{tabular}{|c|c|c|c|c|c|c|c|}
\hline \multirow{2}{*}{$\begin{array}{l}\text { Antibiotic } \\
\text { against which } \\
\text { susceptibility } \\
\text { was observed }\end{array}$} & \multicolumn{7}{|c|}{ Bacterial Species Identified } \\
\hline & $\begin{array}{l}\text { E. coli } \\
(n=69)\end{array}$ & $\begin{array}{l}\text { Klebsiella } \\
\text { spp. } \\
(\mathrm{n}=12)\end{array}$ & $\begin{array}{l}\text { Pseudomonas } \\
\text { spp. } \\
(\mathrm{n}=10)\end{array}$ & $\begin{array}{l}\text { Enterococci } \\
\text { spp. } \\
(\mathrm{n}=6)\end{array}$ & $\begin{array}{l}\text { Staph. } \\
\text { saprophyticu } \\
\text { s } \\
(\mathrm{n}=3)\end{array}$ & $\begin{array}{l}\text { Proteus } \\
\text { spp. } \\
(\mathrm{n}=4)\end{array}$ & $\begin{array}{l}\text { Enterob } \\
\text { acter } \\
\text { spp. } \\
(\mathrm{n}=3) \\
\end{array}$ \\
\hline Amoxicillin & $16(23.19)$ & $0(0.0)$ & -- & $1(16.67)$ & $1(33.33)$ & $0(0.0)$ & $0(0.0)$ \\
\hline Cephradin & $17(24.63)$ & $2(16.67)$ & --- & $0(0.0)$ & $2(75.0)$ & $1(25.0)$ & $0(0.0)$ \\
\hline Cotrimoxazole & $17(24.64)$ & $1(8.33)$ & -- & $1(16.67)$ & $1(25.0)$ & $0(0.0)$ & $0(0.0)$ \\
\hline Cefotaxim & $45(65.22)$ & $4(33.33)$ & $4(40.0)$ & $2(33.33)$ & $2(75.0)$ & $2(50.0)$ & $2(75.0)$ \\
\hline Ceftazidime & $57(82.61)$ & $5(41.67)$ & $4(40.0)$ & $2(33.33)$ & $2(75.0)$ & $2(50.0)$ & $2(75.0)$ \\
\hline Ceftriaxone & $38(55.07)$ & $4(33.33)$ & $3(30.0)$ & $2(33.33)$ & $2(75.0)$ & $3(75.0)$ & $2(75.0)$ \\
\hline Ciprofloxacin & $28(40.58)$ & $2(16.67)$ & $3(30.0)$ & $1(16.67)$ & $2(75.0)$ & $1(25.0)$ & $1(25.0)$ \\
\hline Nalidixic acid & $12(17.39)$ & $1(8.33)$ & --- & $1(16.67)$ & $1(25.0)$ & $1(25.0)$ & $0(0.0)$ \\
\hline Nitrofurantoin & $44(63.77)$ & $8(66.67)$ & --- & $4(66.67)$ & $1(25.0)$ & $2(50.0)$ & $1(25.0)$ \\
\hline Gentamicin & $35(50.72)$ & $3(25.0)$ & $2(20.0)$ & $2(33.33)$ & $1(33.33)$ & $0(0.0)$ & $1(25.0)$ \\
\hline Doxicycline & $8(11.59)$ & $0(0.0)$ & ---- & $0(0.0)$ & $1(25.0)$ & $0(0.0)$ & $0(0.0)$ \\
\hline Imipenem & $68(98.55)$ & 11(91.67) & $9(90.0)$ & $6(100.0)$ & $3(100.0)$ & $4(100.0)$ & $3(100.0)$ \\
\hline Aztreonam & $41(59.42)$ & $5(41.67)$ & $2(20.0)$ & $3(50.0)$ & -- & $3(75.0)$ & $2(75.0)$ \\
\hline Amikacin & $57(82.61)$ & $9(75.0)$ & $6(60.0)$ & $3(50.0)$ & $3(100.0)$ & $2(50.0)$ & $2(75.0)$ \\
\hline
\end{tabular}

Note: Figures in parentheses indicate percentage

Antibiogram of organisms in the present study showed varying susceptibility pattern. Escherichia coli and Klebsiella spp. showed higher sensitivity to imipenem (91.67-98.55\%) and amikacin (75 to $82.61 \%)$. It was observed that Esch. coli showed higher sensitivity against ceftazidime $(82.61 \%)$ and 
moderate sensitivity against cefotaxim (65.22\%), nitrofurantoin $(63.77 \%)$, ceftriaxone $955.07 \%$ ) and gentamicin $950.72 \%$ ), whereas Klebsiella species showed lower sensitivity to ceftazidime (941.67\%), cefotaxim (933.33\%) and ceftriaxone (933.33\%). About $82.61 \%$ of Esch. coli was resistant to nalidixic acid followed by cotrimoxazole $(75.36 \%)$ and ciprofloxacin $(57.97 \%)$. Sharmin ${ }^{22}$ reported similar sensitivity pattern of Esch. coli and Klebsiella spp. against imipenem (998.9-100\%), amikacin (70-75.5\%), ceftazidime (89.7-45\%), cefotaxim (66.6-40\%), ceftriaxone (20-54\%) and least sensitivity against other drugs. Ling et $\mathrm{al}^{23}$ from China reported that $40.8 \%$ of Esch. coli was resistant to ciprofloxacin which was lower than the present study. $\operatorname{Easin}^{24}$ reported similar findings. She observed that Klebsiella was highly resistant (70$100 \%)$ to all drugs except ciprofloxacin $(100 \%)$ and imipenem (80\%). Hossain et al ${ }^{17}$ reported, $43 \%$ of Esch. coli was resistant to ciprofloxacin and $29 \%$ to ceftriaxone. Study done in Holy Family Red Crescent Hospital ${ }^{24}$ reported that $26 \%$ of Esch. coli were resistant against ciprofloxacin and 25\% against ceftriaxone. Islam ${ }^{4}$ reported minimum resistance against ciprofloxacin (18.2\%) and ceftriaxone $(20.0 \%)$. Sharif ${ }^{26}$ showed only $15 \%$ of Esch. coli were resistant to ceftriaxone and ciprofloxacin. Resistance pattern against ciprofloxacin and ceftriaxone studied by above mentioned authors were not consistent with the present study. Reason of these variations might be due to the fact that as they year's passing ciprofloxacin and ceftriaxone are becoming more resistant against Esch. coli probably due to over and irrational use and easy availability of the drug in our country. Mazzulli ${ }^{27}$ from Canada, reported that only $1.8-2.3 \%$ of Esch. coli were resistant to ciprofloxacin. Reason might be due to rational use of drugs in their country and these drugs are not easily available.

In the present study Pseudomonas spp. showed higher sensitivity to imipenem (91.67\%) and amikacin $(75.0 \%)$. Least sensitivity was showed against ceftazidime (40\%) and other antibiotics (20 to $30 \%$ ). Sharmin ${ }^{22}$ and Chowdhury ${ }^{15}$ from Bangladesh reported similar sensitivity to above antibiotics. Contrary to the present study higher sensitivity to ceftazidime $(62.5 \%)$ was reported by Kawsar $^{20}$. Similarly Wadud et $\mathrm{al}^{28}$, Islam et $\mathrm{al}^{4}$ and Shahnaz et $\mathrm{al}^{21}$ from Bangladesh reported higher sensitivity pattern to ceftazidime, ciprofloxacin, ceftriaxone and gentamicin. Pseudomonas species can rapidly develop resistance especially when single drug is employed due to frequent mutations and its own innate mechanisms of antibiotic resistance ${ }^{24}$. In this study, Enterococci, Enterobacter and Proteus showed $100 \%$ sensitivity to imipenem. Enterobacter species showed $75.0 \%$ sensitivity to ceftriaxone and ceftazidime. Proteus species and Enterococci species showed 50\% and $33.33 \%$ sensitivity to ceftriaxone and ceftazidime respectively. Contrary to our findings, moderate sensitivity against ceftriaxone (75\%) and ciprofloxacin (50.0\%) against Enteococcus were reported by Kawsar et $\mathrm{al}^{20}$ and Shahnaz et $\mathrm{al}^{25}$. The sensitivity pattern to various antimicrobial agents varies in different studies, in different parts of the same country at different times in the same hospital. This might be due to emergence of resistanct bacteria caused by the indiscriminate use of antimicrobial agents ${ }^{29}$.

In this study it was observed that $100 \%$ of $S$. saprophyticus were sensitive to imipenem and amikacin. Better sensitivity was observed to ciprofloxacin, ceftriaxone and ceftazidime. Similar findings were observed by Shahnaz et $\mathrm{al}^{21}$ from Bangladesh.

\section{Conclusion}

The prevalence of antimicrobial resistance among microorganisms that cause UTI is increasing worldwide and is a major factor in selecting antibiotics for treatment. Regular monitoring is required to establish reliable information about susceptibility pattern of urinary pathogens for optimal empirical therapy of patients with urinary tract infection. The emergence and spread of resistance can be reduced through appropriate and careful use of antimicrobial agents and increasing awareness among the population to the hazards of inappropriate antimicrobial use through public health education campaign.

\section{References}

1. Goddard J, Turner AN, Cumming AD, Stewart LH. Kidney and urinary tract disease. In: Boon NA, Colledge NR, Walker BR, Hunter JAA editors. Davidson's principles and practice of Medicine, $20^{\text {th }}$ edition. Churchill Livingstone, Edinburg. 2006: pp. 455-511

2. Lee LB, Neild HG. Urinary tract infection. Medicine 2007;35(8):423-428

3. Sobel JD, Kaye D. Urinary Tract Infections. In: Mandell G, Bennet J, Dolin R, editors. Principle and practice of infectious disease. $4^{\text {th }}$ edition. Churchill Livingstone, 2000:pp. 875-905

4. Islam NM, Kibria GS, Ali YM. Prevalence of urinary pathogens and sensitivity patterns in Faridpur, Bangladesh. Bangladesh Journal of Pathology 2002;17(1):14-16

5. Calvin MK. Urinary Tract Infections in Females. Clin Infect Dis 1994;18;1-12 
6. Jawetz E andMelninick, 1995. Clinical correlations: urinary tract in Medical Microbiology, $20^{\text {th }}$ Ed. London, UK, Prentice Ball Intl. Inc. p.634

7. Graham JC, Galloway A. The laboratory diagnosis of urinary tract infection. Journal of Clinical Pathology 2001;54: 911-919

8. Pappas GP. Laboratory in the diagnosis and management of urinary tract infections. Medical Clinics of North America 1991;75:3312-325

9. Alon U, Davidai G, Berant M, Merzbach D. Five year survey of changing patterns of susceptibility of bacterial uropathogens to Trimethoprim-Sulphamethaxasole and other antimicrobial agents. Antimicrobial Agnts and Chemotherapy 1987;31:126-28

10. Bacheller CD, Bernstein MJ. Urinary tract infections. Medical Clinics of North America 1997; 8: 719-729

11. Cheesbrough M. Summary of the clinical and laboratory features of microorganisms. In: District Laboratory Practice in Tropical Countries. Part 2. Cambridge University Press, UK 2000: PP 157-266

12. Bauer AW,Kirby WMM, Sherris JG, Turch M. Antibiotic susceptibility testing by a standardized single disc method. Americal Journal of Clinical Pathology 1996;45:493-496

13. Collee JG, Duguid JP, Fraser AG, Marmion BP. Laboratory strategies in the diagnosis of infectious syndromes. In: Collee JG, Barrie MP, Farser AG, Simmons A. editor. Practical Medical Microbiology, $14^{\text {th }}$ edition. Churchill Livingston. NewYork 1996;pp.53- 93

14. Forbes BA, Sahm DF,Weissfeld AS. Laboratory cultivation and isolation of bacteria. In: Bailey and Scott's Diagnostic Microbiology, $10^{\text {th }}$ edition. Mosby,St.Louis, Missouri 1998;pp. 150-160

15. Chowdhury MA. Urinary tract infection in pregnancy. A bacteriological study. [M.Phil Microbiology Thesis]; University of Dhaka. 1998; PP. 87-105

16. Khaleque SA, Islam KMN, Ishaq M, Kamal N. Pattern of bacterial growth of 3022 urine samples cultured in a private laboratory. Bangladesh Private Medical Practioners Journal 1990;1:9-13

17. Hossain M, Sultana S, Hanif M, Saha K Samir. Screening of urinary tract infection (UTI) in febrile infants. Bangladesh Private Medical Practitioners Journal 2002;8(1):13-17

18. Bhuiyan MMR, Abdullah SAH. Study of adult male patients with burning micturition. Sir Salimullah Medical College Journal 1994;2(2): 46-49
19. Hames L, Rice CE. Antimicrobial resistance of urinary tract isolates in acute uncomplicated cystitis among college-aged women: choosing a first line therapy. Journal of American College of Health. 2007; 56(2): 153-6

20. Kawsar NM, Khan NK, Rahman ASMM. Astudy on nosocomial infections and antibiotic resistance pattern of the isolates in ICU patients. Bangladesh Armed Forces Medical Journal 2002;30:9-13

21. Shahnaz S, Murshed M, Rahman T. Urinary pathogens and its culture sensitivity patterns in Holy Family Red Crescent Medical College Hospital. Bangladesh Private Medical Practitioners Journal. 2005;11(1):19-21

22. Sharmin S. Use of chromogenic media (Urochrom II) for detection of uropathogen. [M.Phil Microbiology Thesis]; University of Dhaka. 2005: pp. 55-68

23. Ling TKW, Xiong J, Yu Y, Lee CC,Ye H, Hawkey PM et al. Multicenter antimicrobial susceptibility survey of Gram-negative bacteria isolated from patients with community acquired infection in the people's Republic of China. Antimicrobial Agents and Chemotherapy 2006; 50 : 374-378

24. Easin S. Study on aerobic bacterial infections in nephritic children and it's relation with serum immunoglobulin G (IgG). M.Phil (Microbiology) Thesis; University of Dhaka. 2006, July; pp. 60-65

25. Shahnaz S, Murshed M, Rahman T. Urinary pathogens and its culture sensitivity patterns in Holy Family Red Crescent Medical College Hospital. Bangladesh Private Medical Practitioners Journal. 2005;11(1):19-21

26. Sharif MNH. Diagnosis and detection of UTI with special reference to E. coli O-serogroup. MD (Nephrology) Thesis; University of Dhaka. 1999

27. Mazzulli T. Antimicrobial resistance trends in common urinary pathogens. Canadian Journal of Urology 2001; 8 suppl 1:2-5

28. Wadud ABMA, Rahman ASMM, Wasey AFSA, Khan AA, Jubaida N. Antibiotic resistance in Pseudomonas aeruginosa strains isolated from clinical specimens. Bangladesh Armed Forces Medical Journal. 2004; December: 31-35

29. Talukder MAS. Sensitivity pattern of positive urine culture in a teacging Hospital. Bangladesh Renal Journal 1997; 6: 46-52 